\title{
Machiavellianism and Elicitation of Self-Disclosure in a Competitive Friendship
}

\author{
Chi-Fai Lo',2,3 \\ ${ }^{1}$ Institute of Theoretical Physics and Department of Physics, The Chinese University of Hong Kong, Hong Kong, China \\ ${ }^{2}$ Department of Psychology, Sociology and Politics, Sheffield Hallam University, Sheffield, UK \\ ${ }^{3}$ Social and Human Sciences Section, SCOPE, City University of Hong Kong, Hong Kong, China \\ Email: edcflo@gmail.com
}

How to cite this paper: Lo, C.-F. (2021). Machiavellianism and Elicitation of SelfDisclosure in a Competitive Friendship. $P s y$ chology, 12, 409-424.

https://doi.org/10.4236/psych.2021.123026

Received: February 4, 2021

Accepted: March 28, 2021

Published: March 31, 2021

Copyright $\odot 2021$ by author(s) and Scientific Research Publishing Inc. This work is licensed under the Creative Commons Attribution International License (CC BY 4.0).

http://creativecommons.org/licenses/by/4.0/

\section{Open Access}

\begin{abstract}
The present study investigated the influence of Machiavellianism and friendship competition on the elicitation of self-disclosure from others within friendship dyads. Male $(\mathrm{N}=120)$ and female $(\mathrm{N}=70)$ participants aged 17 to 60 years $(M=29.15, S D=12.26)$ completed a questionnaire containing preliminary demographic questions, Mach IV Scale, Opener Scale and Interpersonal Competition Index. The regression analysis has revealed that Machiavellianism and friendship competition are reliable predictors of the ability to elicit self-disclosure from others, and these results coincide with those of correlation analysis. This study represents the very first attempt to investigate the Machiavellian personality correlates associated with the tendency to elicit self-disclosure from others, and its findings may help shed light upon the direction of future research.
\end{abstract}

\section{Keywords}

Machiavellianism, Elicitation, Self-Disclosure, Competition, Friendship

\section{Introduction}

\subsection{Machiavellianism}

Being one of the so-called "Dark Triad" personality traits, i.e. Machiavellianism, narcissism, and psychopathy (Paulhus \& Williams, 2002), in modern psychology, Machiavellianism has come to be associated with tendencies to disdain conventional morality, lack empathy and sincerity, manipulate or exploit others in 
social interactions, and achieve self-interests via deception (Christie \& Geis, 1970; Vecchio \& Sussman, 1991; Fehr, Samsom, \& Paulhus, 1992; McHoskey, 1995; McHoskey, Worzel, \& Szyarto, 1998; Wilson, Near, \& Miller, 1998; Wastell \& Booth, 2003; Sherry et al., 2006; Jones \& Paulhus, 2009; Ali \& Chamorro-Premuzic, 2010; Bereczkei, Birkas, \& Kerekes, 2010; Rauthmann, 2012; Furnham et al., 2013). The term "Machiavellian" refers to an individual associated with tendencies to distrust others, engage in amoral manipulation, seek control over others, and seek status for oneself (Fehr et al., 1992; McHoskey, 1999; Dahling et al., 2009). Machiavellians have also been shown to be resistant to influence by others, cognitively oriented, disinterested in interpersonal closeness, and motivated by self-interest (Fehr et al., 1992; McHoskey, 1999; Wastell \& Booth, 2003). Moreover, many studies have indicated that Machiavellianism is negatively correlated with agreeableness and conscientiousness as well as with emotional intelligence, but positively correlated with neuroticism of the Big Five personality constructs (Paulhus \& Williams, 2002; Austin et al., 2007; Andrew et al., 2008; Vernon et al., 2008; Veselka et al., 2012; Jonason \& Kavanagh, 2010).

Machiavellians are not only good at putting the blame upon others and low on forgiveness, but they are also deeply cynical and show a detached, controlling coolness (Christie \& Geis, 1970; Lyons \& Aitken, 2010). Due to the lack of emotional attachment, there may be little that holds Machiavellians back from harming others for the sake of achieving success. It is not surprising that Machiavellianism influences sexual (Jonason et al., 2009; McHoskey, 2001), romantic (Ragsdale \& Brandau-Brown, 2005; Jonason \& Kavanagh, 2010) and working (Chen, 2010; Kiazad et al., 2010) relationships, too. In particular, recent research findings have indicated that employees high in Machiavellianism are quite disruptive to the effective functioning of organizations (Dahling et al., 2009; Kessler et al., 2010; Kish-Gephart et al., 2010; O’Boyle et al., 2012). For instance, these employees are more likely to steal (Fehr et al., 1992; Harrell \& Hartnagel, 1976), are economically opportunistic and less cooperative (Sakalaki et al., 2007), have lower job satisfaction and higher turnover (Fehr et al., 1992; Wilson et al., 1996), engage in unethical and counterproductive work behaviours (Kish-Gephart et al., 2010; O'Boyle et al., 2012). Furthermore, Machiavellians place little importance on establishing close, intimate relationships, but these relationships do provide Machiavellians with opportunities for emotional manipulation, such as coercion and pleasure induction, and subsequent reward (Lyons \& Aitken, 2010; Brewer et al., 2014, Lo \& Ng, 2019). All in all, increasing attention has been drawn towards the study of Machiavellianism in recent years due to its prominence in subclinical populations and influence on psychological adjustment (McHoskey, 1999; Martin et al., 2012).

\subsection{Competition in Friendship}

Humans are social animals and friendship is certainly a significant form of interpersonal relationships, as demonstrated by the considerable amount of time 
spent with friends. It is commonly agreed that the term friendship refers to the cooperative, supportive and caring behaviour among people, and that friendships are important because of the time that was spent with friends, the pleasure derived from friendships and the increasing role of friendships in filling our social needs (Perlman, 2016). Research findings also suggest that friendship is a critical determinant of personal happiness, hopefulness, self-esteem and self-image (Foster, 2005). For instance, as pointed out by Holt-Lunstad (2016), having more and better relationship is critical for having better physical and mental health. Both Erdley and Day (2016) and King et al. (2016) emphasize how lack of friendship is linked with loneliness, depression, anxiety and being low in self-esteem as well as how friendship leads to smoother school adjustment, higher psychosocial adjustment and better quality of life. In addition, Morrison and Cooper-Thomas (2016) stress organizational benefits of friendship and claim that employees with a best friend at work are seven times as likely as to be engaged in their jobs, more productive, and less likely to get injured on the job.

In spite of the various benefits of friendship, there are downsides of friendship, too. Competition is one of the most disliked aspects of friendship and may influence the selection of friends (Bleske \& Buss, 2000). Although interpersonal competition is ubiquitous in all arenas of human life: within the family, in school, in the sports ground, in the workplace, among peers, etc., yet competition in friendship has received very little attention in the literature (Singleton \& Vacca, 2007). This may be attributed to the spurious dichotomy posed between competition and cooperation; competition was often considered to be basically negative whereas cooperation was identified to be positive and constructive (Deutsch, 1949, 1973; Johnson \& Johnson, 1989; Van de Vliert, 1999; Fülöp, 2004). Regarding the impact of competition on friendship, it is commonly believed that competition is an inevitable component of the human condition and social comparison among close others, especially some benign forms of competition, might actually be a great way to motivate each other (or, at the very least, lead to some fun) and help one realize one's own abilities (Sullivan, 1953; Tassi \& Schneider, 1997). On the contrary, competition has also been thought of as detrimental to maintaining close, quality friendships, especially when it becomes excessive, because it causes tension and ill feelings as well as interferes with the satisfaction of personal needs as compared with cooperation (Deutsch, 1949; Tesser \& Moore, 1990; Berndt, 1996; Singleton \& Vacca, 2007). Particularly, Rubin (1985) has asserted that competition undermines the emotional support that friendship requires. Hence, managing competitiveness in our friendships is of utmost importance. In a survey conducted among professionals concerning what they disliked about their friendships, Sapadin (1988) indeed observed that "competition" turned out to be the most popular response of both men and women with respect to their same-sex friends. Moreover, related research suggests that there exists more interpersonal competition between male friends than between female friends (i.e. males are more competitive than females) and that 
this gender difference seems to result from the gender-role expectations and socialization (Lever, 1978; Spence \& Helmreich, 1983; Rubin, 1985; Werking, 1997). For instance, women seldom acknowledge competition with their friends but competition seems to be a "theme" that runs through men's relationships with one another (Rubin, 1985). Nevertheless, competition in cross-sex friendships does not receive much attention in the literature, and this may imply that there exists less competition between cross-sex than between same-sex friends (Werking, 1997).

\subsection{Elicitation of Self-Disclosure}

Self-disclosure is defined as the act of revealing details about oneself (including thoughts, feelings, aspirations, goals, failures, successes, fears, dreams, favourites, etc.) to others, and it is crucial for developing and reinforcing intimacy, trust and liking within human relationships (Berg \& Derlega, 1987; Monsour, 1992; Collins \& Miller, 1994). Of course, this may involve risk and vulnerability on the part of the person sharing the information (Wicker et al., 2005). Self-disclosure not only allows us to open up and disclose more with people who disclose too, but it is also a reciprocal process in which the more one discloses to others, the more they will be willing to do the same, thus leading to trust that strengthens the relationship (Steinberg, 2007). However, too much disclosure early in a relationship may not facilitate its development for it might be viewed as being insecure and can lead to rejection because of not being liked or accepted (Steinberg, 2007). Self-disclosure consists of two major aspects, namely the depth or intimacy of information disclosed, and the breath or amount of exchanged information (Cosby, 1973). When one's private information is being disclosed, the disclosure is high in depth; on the other hand, when one discloses a wide range of topics about himself/herself, such a disclosure is high in breadth.

While individuals have a propensity to disclose "high" or "low" amounts of personal information (Cosby, 1973), similar individual differences can also be found in the ability to elicit intimate self-disclosure from interaction partners (Miller et al., 1983; Colvin \& Longueuil, 2001). In order to assess the individual differences in this ability quantitatively, Miller et al. (1983) developed the Opener Scale, which is a 10 -item measure rated on a 5-point Likert scale. Despite its brevity, the Opener Scale has been shown to be both reliable and valid. According to the scale, individuals termed as "High Openers" (i.e. the high scorers) were able to elicit a greater amount of more intimate self-disclosure from their targets than "Low Openers" (i.e. the low scorers) in get-acquainted contexts (Miller et al., 1983; Shaffer et al, 1990; Pegalis et al, 1994). High Openers are liked better than Low Openers by unacquainted partners because High Openers tend to be socially skilled with warm and agreeable personalities as well as are more attentive to their partners. Research evidence has also demonstrated that High Openers score higher on measures of receptiveness, responsiveness and agreeableness (Colvin \& Longueuil, 2001; Miller et al., 1983; Wheeless \& Grotz, 
1977; Barrett \& Pietromonaco, 1997). Accordingly, these findings imply that High Openers may be linked to greater satisfaction in the intimate context of a long-term relationship (Miller et al., 1983; Hendrick et al., 1988). In other words, High Openers may have more close friends than Low Openers. Moreover, obvious gender differences were observed; men score significantly lower on the Opener Scale than women (Miller et al., 1983; Pegalis et al., 1994; Colvin \& Longueuil, 2001). This is consistent with the research finding that women are more motivated to seek harmonious interpersonal relationships than men (Bakan, 1966; Vogt \& Colvin, 2003).

\subsection{Objectives and Hypotheses}

The current study investigates the relationship between Machiavellianism and elicitation of self-disclosure in a competitive friendship. Machiavellians place little importance on intimate relationships and report friendships of poor quality, but they regard these relationships as good opportunities for emotional manipulation and subsequent reward (Lyons \& Aitken, 2010). In particular, Machiavellian individuals intentionally use self-disclosure as a manipulative strategy to maximize personal gain (Jones et al., 1979; Rauthmann, 2012). A recent study of how Machiavellianism and competition influence self-disclosure within friendship dyads has revealed that Machiavellianism and friendship competition predict the honesty-accuracy of self-disclosure but not the amount or positiveness-negativeness of information disclosed (Brewer et al., 2014). Whereas Machiavellian personalities appear to make strategic self-disclosures, the contrasteliciting self-disclosure from others-in the Machiavellian personality has yet to be investigated. A study of the relationship between Machiavellianism and elicitation of self-disclosure will beyond question help shed light upon the Machiavellian personalities in this regard.

Three measures, namely the Mach IV Scale developed by Christie and Geis (1970), the Opener Scale designed by Miller et al. (1983) and the Interpersonal Competition Index constructed by Singleton and Vacca (2007), are employed to evaluate agreement with Machiavellian beliefs, to measure individual differences in the ability to elicit self-disclosure from others, and to assess the intensity of competition, respectively. Equipped with these three instruments, the current study has the following specific objectives:

1) To explore the relationship between Machiavellianism and elicitation of self-disclosure in a competitive or cooperative friendship;

2) To test the hypothesis that females tend more likely to be Low Machs and High Openers as well as to exhibit Low Competitiveness than males.

The proposed hypothesis is based upon the fact that men report higher levels of Machiavellianism than women (O’Connor \& Simms, 1990; McHoskey, 1999, 2001), women use disclosure more than men in close friendships (Dindia \& Allen, 1992), and women are more skilful in eliciting self-disclosure from others than men (Miller et al., 1983; Pegalis et al., 1994; Colvin \& Longueuil, 2001). 


\section{Method}

\subsection{Participants}

A total of 190 individuals (age 17 to $60, \mathrm{M}=29.15, \mathrm{SD}=12.26$ ) were recruited to participate in this study by convenience sampling and snowball sampling. The sample consists of 120 men (age 17 to $60, \mathrm{M}=29.36, \mathrm{SD}=12.54$ ) and 70 women (age 17 to $57, \mathrm{M}=28.80, \mathrm{SD}=11.86$ ). Of the 190 participants, 14 are secondary school graduates, 75 are either studying university education now or university graduates, and 101 are either postgraduate students now or have received postgraduate degrees. None of the participants received any financial reward for participation.

\subsection{Measures}

Three instruments were administered to collect the research data. The first instrument is the Mach IV Scale developed by Chrisie and Geis (1970), the second one is the Opener Scale designed by Miller et al. (1983), and the third one is the Interpersonal Competition Index constructed by Singleton and Vacca (2007).

\subsubsection{Mach IV Scale}

The Mach IV Scale (Christie \& Geis, 1970) contains 20 items rated on a five point Likert scale ( $1=$ strongly disagree to $5=$ strongly agree) and is used to evaluate agreement with Machiavellian beliefs in interactions with others, morality and cynicism. The twenty items are divided into three categories, namely 9 items on the use of tactics in interpersonal relationship, 9 items on cynical views of human nature and 2 items on lacking of morality. As ten items of the scale show avoidance of Machiavellian attitude instead of acceptance, they have been reverse scored. The total score ranges from 20 to 100. A basic premise of the Mach IV scale is that high scores indicate higher endorsement of Machiavellian views and behaviour whilst low scores simply imply the opposite. The term "High Machs" commonly refers to the participants high in Machiavellian trait and those participants low in Machiavellian trait are labelled as "Low Machs", even though most current research tends to investigate Machiavellianism on a continuum. People scoring above 60 are identified as High Machs whereas those scoring 60 or below are known as Low Machs. This scale has demonstrated high internal consistency as well as acceptable reliability and validity in various previous studies (Fehr et al., 1992). Example items include "Honesty is the best policy in all cases." and "Anyone who completely trusts anyone else is asking for trouble". Besides, the name "Barnum" in Item 17 has been replaced by "people" in order that the local people in Hong Kong can understand the question better.

\subsubsection{Opener Scale}

The Opener Scale (Miller et al., 1983) contains 10 items rated on a five point Likert scale $(1=$ strongly disagree to $5=$ strongly agree $)$, and is used to measure individual differences in the ability to elicit self-disclosure from others. The ten 
items can be grouped into three categories, namely perceived reactions of others (e.g. Item 6), interest in listening to others (e.g. Item 7), and interpersonal skills (e.g. Item 10). The total score has a minimum of 10 and a maximum of 50. High Openers who score above 30 are better liked and elicit more self-disclosure from their interaction partners than Low Openers who score 30 or below. This scale has been a useful tool for studying the underlying processes of self-disclosure and the dynamics of social interactions (Pegalis et al., 1994; Vogt \& Colvin, 2003). Example items include "People trust me with their secrets." and "I'm sympathetic to people's problems."

\subsubsection{Interpersonal Competition Index}

The Interpersonal Competition Index (Singleton \& Vacca, 2007) contains 7 items concerning competition within various domains in which friends may compete with one another. The index regards the interpersonal competition as a process of comparison motivated by the desire to outperform the others, so it actually measures the intensity of competition instead of the frequency. Each item is rated on a five point Likert scale $(1=$ strongly disagree to $5=$ strongly agree), with the total score lying between 7 and 35, and Item 3 has been reverse scored. High Competitiveness is defined by a score above 21; otherwise we have Low Competitiveness. Example items include "I don't like my friend to get better grades than I do" and "I do not mind losing arguments with my friend".

\subsection{Procedures}

A questionnaire comprising the 20 items of Mach IV Scale, the 10 items of Opener Scale, the 7 items of Interpersonal Competition Index, and a few demographic items (like the gender, age, education level, etc.) was designed. All the required briefing and de-briefing information were provided with the questionnaire. A webpage was created so that the study could be conducted online. While 98 individuals participated the online survey, 92 participants returned hardcopies of the completed questionnaire.

\section{Results}

\subsection{Descriptive Statistics}

The reliability of the three scales, namely the Mach IV Scale, the Opener Scale and the Interpersonal Competition Index, was analysed using the SPSS. The Cronbach's alpha values of the Mach IV Scale is acceptable $(\alpha=0.618)$ whilst both the Opener Scale and the Interpersonal Competition Index exhibit strong Cronbach's alpha values (Opener Scale: $\alpha=0.854$; Interpersonal Competition Index: $\alpha=0.798$ ). Before performing the correlation analysis, normality checks for the three scales were conducted. The following descriptive statistics data were obtained: Mach IV Scale $(\mathrm{M}=56.54, \mathrm{SD}=6.86$, Skewness $=-0.027$ with $\mathrm{SE}=$ 0.176 , Kurtosis $=0.236$ with $\mathrm{SE}=0.351)$, Opener Scale $(\mathrm{M}=35.87, \mathrm{SD}=5.59$, Skewness $=-0.028$ with $\mathrm{SE}=0.176$, Kurtosis $=-0.062$ with $\mathrm{SE}=0.351)$ and In- 
terpersonal Competition Index $(\mathrm{M}=17.61, \mathrm{SD}=4.74$, Skewness $=-0.050$ with $\mathrm{SE}=0.176$, Kurtosis $=-0.281$ with $\mathrm{SE}=0.351)$. It is apparent that the skewness and kurtosis data all seem to imply normal distributions. The normality is also confirmed by the Shapiro-Wilk test results: Mach IV Scale (S-W $=0.990, \mathrm{df}=$ $190, \mathrm{p}=0.223)$, Opener Scale $(\mathrm{S}-\mathrm{W}=0.986, \mathrm{df}=190, \mathrm{p}=0.057)$ and Interpersonal Competition Index $(\mathrm{S}-\mathrm{W}=0.990, \mathrm{df}=190, \mathrm{p}=0.217)$. In addition, other results like the Q-Q plots, box plots and histograms with normal distribution curves were scrutinized such that the parametric assumptions of the three scales could be checked.

Finally, scatter plots with lines of best fit were examined to check for the linear assumptions involving the Pearson correlations. Results of the scatter plots indicate that all the correlations are linear. As such, the Pearson correlation coefficients among the three scales were computed using the SPSS as follows:

1) Pearson correlation between Mach IV Scale and Opener Scale is $(r=$ $-0.260, p<0.001, \mathrm{n}=190,2$-tailed);

2) Pearson correlation between Mark IV Scale and Interpersonal Competition Index is ( $\mathrm{r}=0.143, p=0.049, \mathrm{n}=190,2$-tailed);

3) Pearson correlation between Opener Scale and Interpersonal Competition Index is ( $\mathrm{r}=-0.248, p=0.001, \mathrm{n}=190,2$-tailed $)$.

As shown by the Pearson correlation coefficients, the Mach IV Scale positively correlates with the Interpersonal Competition Index whereas both of them exhibit a material negative correlation with the Opener Scale.

\subsection{Regression Analysis}

To investigate the influence of Machiavellianism and friendship competition on the capability of eliciting self-disclosure, standard multiple linear regression was conducted with Machiavellianism and friendship competition being entered simultaneously. A significant regression equation was found $(\mathrm{F}(2,187)=11.863, p$ $<0.001)$, with an $R^{2}$ of 0.113 . Participants' predicted Opener Scale score is equal to $50.869-0.186 \times($ Mach IV Scale score $)-0.254 \times$ (Interpersonal Competition Index score). Participant's Opener Scale score decreases 0.186 unit for each unit of Mach IV Scale score and 0.254 unit for each unit of the Interpersonal Competition Index score. Both Mach IV Scale score $(\beta=-0.229, p=0.001)$ and Interpersonal Competition Index score $(\beta=-0.215, p=0.002)$ are significant predictors of Opener Scale score. This is in agreement with the results of correlation analysis.

\subsection{Independent Samples $t$-Test}

An independent samples $t$ test was performed comparing the mean Opener Scale scores of High Machs and Low Machs. The test results show that Low Machs (M $=36.39, \mathrm{SD}=5.51, \mathrm{n}=135)$ are more capable of eliciting self-disclosure from others than High Machs $(\mathrm{M}=34.58, \mathrm{SD}=5.63, \mathrm{n}=55), t(188)=2.04, \mathrm{p}=0.043$, two-tailed. The mean difference between the two groups is 1.81 , and the $95 \%$ 
confidence interval (CI) for the estimated population mean difference is between 0.06 and 3.56 .

Likewise, the same $t$ test was performed comparing the mean Opener Scale scores of High Competitiveness and Low Competitiveness. Low Competitiveness $(\mathrm{M}=36.29, \mathrm{SD}=5.45, \mathrm{n}=153)$ is more favourable for elicitation of self-disclosure from others than High Competitiveness $(\mathrm{M}=34.11, \mathrm{SD}=5.89, \mathrm{n}=37), t(188)=$ $2.15, p=0.032$, two-tailed. The mean difference between the two groups is 2.19 , and the $95 \% \mathrm{CI}$ for the estimated population mean difference is between 0.18 and 4.19 .

Beyond question these $t$ tests have drawn conclusions that are consistent with both the correlation analysis and the multiple linear regression analysis.

\subsection{Gender Differences}

\subsubsection{Descriptive Statistics}

Reliability and normality checks for the three scales were applied to the samples of the two genders, and both properties were found to remain valid. The details of the analyses of both reliability and normality are: 1) for males Mach IV Scale $(\alpha=0.603, \mathrm{M}=57.55, \mathrm{SD}=6.82$, Skewness $=0.011$ with $\mathrm{SE}=0.221$, Kurtosis $=$ 0.346 with $\mathrm{SE}=0.438)$, Opener Scale $(\alpha=0.836, \mathrm{M}=34.92, \mathrm{SD}=5.40$, Skewness $=0.176$ with $\mathrm{SE}=0.221$, Kurtosis $=0.241$ with $\mathrm{SE}=0.438)$ and Interpersonal Competition Index $(\alpha=0.817, M=18.32, \mathrm{SD}=4.93$, Skewness $=-0.193$ with $\mathrm{SE}$ $=0.221$, Kurtosis $=-0.138$ with SE $=0.438)$, and 2) for females Mach IV Scale ( $\alpha$ $=0.614, \mathrm{M}=54.80, \mathrm{SD}=6.63$, Skewness $=-0.147$ with $\mathrm{SE}=0.287$, Kurtosis $=$ 0.013 with SE $=0.566)$, Opener Scale $(\alpha=0.870, \mathrm{M}=37.50, \mathrm{SD}=5.57$, Skewness $=-0.426$ with $\mathrm{SE}=0.287$, Kurtosis $=0.241$ with $\mathrm{SE}=0.566)$ and Interpersonal Competition Index $(\alpha=0.734, M=16.39, \mathrm{SD}=4.15$, Skewness $=-0.007$ with $\mathrm{SE}$ $=0.287$, Kurtosis $=-0.615$ with SE $=0.566$ ). The Cronbach's alpha values are acceptable for the Mach IV Scale and strong for the other two instruments. Both the skewness and kurtosis data all seem to imply normal distributions.

In addition, the normality is confirmed by the Shapiro-Wilk test results: 1) for males Mach IV Scale $(\mathrm{S}-\mathrm{W}=0.991, \mathrm{df}=120, p=0.584)$, Opener Scale $(\mathrm{S}-\mathrm{W}=$ 0.981, $\mathrm{df}=120, p=0.080)$ and Interpersonal Competition Index $(\mathrm{S}-\mathrm{W}=0.986$, $\mathrm{df}=120, \mathrm{p}=0.271)$, and 2$)$ for females Mach IV Scale $(\mathrm{S}-\mathrm{W}=0.979, \mathrm{df}=70, p=$ 0.287), Opener Scale ( $\mathrm{S}-\mathrm{W}=0.972, \mathrm{df}=70, p=0.116)$ and Interpersonal Competition Index $(\mathrm{S}-\mathrm{W}=0.982, \mathrm{df}=70, p=0.418)$. Other results like the $\mathrm{Q}-\mathrm{Q}$ plots, box plots and histograms with normal distribution curves were examined to check the validity of the parametric assumptions of the three scales as well. Besides, the correlation analysis shows that the sample of 120 males displays negative correlation between the Opener Scale and the Interpersonal Competition Index with statistical significance $(\mathrm{r}=-0.198, p=0.030, \mathrm{n}=120,2$-tailed), whilst in the sample of 70 females the Opener Scale exhibits a statistically significant negative correlation with both the Mach IV Scale $(\mathrm{r}=-0.348, p=0.003, \mathrm{n}$ $=70,2$-tailed $)$ and the Interpersonal Competition Index $(\mathrm{r}=-0.245, p=0.041, \mathrm{n}$ $=70,2$-tailed). 


\subsubsection{Hypotheis Testing}

To test the hypothesis that females tend more likely to be Low Machs and High Openers as well as to exhibit Low Competitiveness than males, the independent samples $t$ test was performed to compare females' mean scores of the three scales with those of males. Results of the $t$ test are: 1) for Mach IV Scale males ( $\mathrm{M}=$ $57.55, \mathrm{SD}=6.82, \mathrm{n}=120)$, females $(\mathrm{M}=54.80, \mathrm{SD}=6.63, \mathrm{n}=70), \mathrm{t}(188)=2.71$, $p=0.07$, two-tailed, mean difference $=2.75$, and $95 \% \mathrm{CI}=(0.75,4.75) ; 2)$ for Opener Scale males $(\mathrm{M}=34.92, \mathrm{SD}=5.40, \mathrm{n}=120)$, females $(\mathrm{M}=37.50, \mathrm{SD}=$ $5.57, \mathrm{n}=70), \mathrm{t}(188)=3.14, p=0.02$, two-tailed, mean difference $=-2.58$, and $95 \% \mathrm{CI}=(-4.20,-0.96)$; and 3$)$ for Interpersonal Competition Index males $(\mathrm{M}$ $=18.33, \mathrm{SD}=4.93, \mathrm{n}=120)$, females $(\mathrm{M}=16.39, \mathrm{SD}=4.15, \mathrm{n}=70), \mathrm{t}(188)=$ 2.77, $p=0.06$, two-tailed, mean difference $=1.94$, and $95 \% \mathrm{CI}=(0.56,3.32)$. It is obvious that all the differences in the mean scores of the three scales are statistically significant. Accordingly, the test results are in support of the hypothesis.

\subsubsection{Regression Analysis}

Standard multiple linear regression was performed separately for male and female participants, with Machiavellianism and friendship competition being entered simultaneously. Analyses reveal that the Mach IV Scale score $(\beta=-0.309$, $p=0.009)$ is a significant predictor of the Opener Scale score for the females $(\mathrm{F}(2,67)=5.965, p=0.004)$, with an $R^{2}$ of 0.389 , but not for the males. On the other hand, the Interpersonal Competition Index score $(\beta=-0.190, p=0.037)$ significantly predicts the Opener Scale score for the males only $(\mathrm{F}(2,117)=$ $3.740, p=0.027)$, with an $R^{2}$ of 0.245 .

\subsubsection{Independent Samples $t$-Test}

An independent samples $t$ test was performed to the samples of both genders independently in order to compare the mean Opener Scale scores of High Machs and Low Machs in each sample. The same test was also conducted to compare the mean Opener Scale scores of High Competitiveness and Low Competitiveness. However, no statistically significant difference can be found at all.

\section{Discussion}

The present study demonstrated that Machiavellianism and competition influence elicitation of self-disclosure within friendship dyads. The friendship dyads experienced by high Mach individuals and those in competitive friendships are found to be characterized by a less amount of intimate self-disclosure from their interaction partners; that is, High Machs are Low Openers under High Competitiveness. The regression analysis suggests that both Machiavellianism and interpersonal competition in friendship are reliable predictors of the ability to elicit self-disclosure from others, and this is in agreement with the results of both correlation analysis and independent samples t-test. Obviously, this is not a surprise because High Openers score higher on measures of receptiveness, responsiveness and agreeableness. The research findings also show that Machiavellianism 
positively correlates with Competitiveness in friendship. This result is consistent with the fact that Machiavellianism is negatively correlated with agreeableness and conscientiousness. Moreover, by comparing women's mean scores of the three scales with those of men, the hypothesis that women tend more likely to be Low Machs and High Openers as well as to exhibit Low Competitiveness than men is confirmed. Nevertheless, perhaps due to the small sample size, the regression analysis of other gender differences is not so conclusive as one may expect.

The conclusions of the current study are of course restricted by a reliance on self-reported data and information from one member of the friendship dyads only. As friendships are dyadic, the perception of the other friend in the dyad is also important for establishing the processes involved in developing intimacy and closeness. A dyad approach provides valuable opportunities for future research. In addition, the findings of the present study are limited to adult friendships, and almost all the participants have at least tertiary education. Thus, there may be possible biases with respect to age and education. A sample of larger size and wider scope will help reduce the biases in future studies. Likewise, due to the small sample size all the analyses cannot be performed within either same-sex friendship dyads or cross-sex friendship dyads. Since biological sex may affect the findings, a large sample of comparable numbers of female and male participants will definitely help resolve the problem. Besides, the correlational questionnaire design does not allow us to infer causality, so longitudinal research monitoring the development and maintenance of friendship dyads is recommended.

In conclusion, both Machiavellianism and interpersonal competition in friendship are found in the current study to be reliable predictors of the ability to elicit self-disclosure from interaction partners, and these results coincide with those of correlation analysis: the Mach IV Scale positively correlates with the Interpersonal Competition Index whereas both of them display a negative correlation with the Opener Scale. This study represents the very first attempt to investigate the Machiavellian personality correlates associated with the tendency to elicit self-disclosure from others, and its findings may help shed light upon the direction of future research. For instance, in recent years the important issue of preventing injuries and deaths in the workplace via voicing safety concerns has attracted much attention towards the industrial organizational domain ( $\mathrm{Lu}$, 2014; Hodges, 2018; Bazzoli et al., 2020; Curcuruto et al., 2020) because of the rising costs of health and safety. Despite that safety in the workplace is a major concern of the employees, some safety concerns are still not being voiced to employers. One possible reason is that an employee may be less likely to voice concerns if their supervisors are Low Openers. Hence, supervisors high in Machiavellianism may constitute a hindrance to safety voicing of the employees.

There are several major limitations in the present study. First, the sample in this study was obtained by convenience sampling and might not represent the 
whole population. Second, data collection was based upon participants' self-report, so their subjective perspectives could not be avoided. Third, all the participants are Chinese living in Hong Kong, so there may be cultural biases in the findings. Further studies with participants other than Chinese could help resolve the problem.

\section{Acknowledgements}

The author would like to thank Dr. Sue Jamison-Powell and Dr. Jonathan Yeung for their useful comments and suggestions.

\section{Conflicts of Interest}

The author declares no conflicts of interest regarding the publication of this paper.

\section{References}

Ali, F., \& Chamorro-Premuzic, T. (2010). The Dark Side of Love and Life Satisfaction: Association with Intimate Relationship, Psychology and Machiavellianism. Personality and Individual Differences, 48, 228-233. https://doi.org/10.1016/j.paid.2009.10.016

Andrew, J., Cooke, M., \& Muncer, S. J. (2008). The Relationship between Empathy and Machiavellianism: An Alternative to Empathizing-Systemizing Theory. Personality and Individual Differences, 44, 1203-1211. https://doi.org/10.1016/j.paid.2007.11.014

Austin, E. J., Farrelly, D., Black, C., \& Moore, H. (2007). Emotional Intelligence, Machiavellianism and Emotional Manipulation: Does EI Have a Dark Side? Personality and Individual Differences, 43, 179-189. https://doi.org/10.1016/j.paid.2006.11.019

Bakan, D. (1966). The Duality of Human Existence: Isolation and Communication in Western Man. Chicago, IL: Rand McNally.

Barrett, L. F., \& Pietromonaco, P. R. (1997). Accuracy of the Five-Factor Model in Predicting Perceptions of Daily Social Interactions. Personality and Social Psychology Bulletin, 23, 1173-1187. https://doi.org/10.1177/01461672972311005

Bazzoli, A., Curcuruto, M., Morgan, J. I., Brondino, M., \& Pasini, M. (2020). Speaking Up about Workplace Safety: An Experimental Study on Safety Leadership. Sustainability, 12, 7458. https://doi.org/10.3390/su12187458

Bereczkei, T., Birkas, B., \& Kerekes, Z. (2010). The Presence of Others, Prosocial Traits, Machiavellianism: A Personality $\times$ Situation Approach. Social Psychology, 41, 238-245. https://doi.org/10.1027/1864-9335/a000032

Berg, J. H., \& Derlega, V. J. (1987). Themes in the Study of Self-Disclosure. In V. J. Derlga, \& J. H. Berg (Eds.), Self-Disclosure, Theory, Research and Therapy (pp. 1-8). New York: Plenum Press. https://doi.org/10.1007/978-1-4899-3523-6_1

Berndt, T. J. (1996). Friendships in Adolescence. In N. Vanzeti, \& S. Duck (Eds.), A lifetime of Relationships (pp. 182-212). Pacific Grove, CA: Brooks/Cole.

Bleske, A. L., \& Buss, D. M. (2000). Can Men and Women Be Just Friends? Personal Relationships, 7, 131-151. https://doi.org/10.1111/j.1475-6811.2000.tb00008.x

Brewer, G., Abell, L., \& Lyons, M. (2014). Machiavellianism, Competition and Self-Disclosure in Friendship. Individual Differences Research, 12, 1-7.

Chen, S. Y. (2010). Relations of Machiavellianism with Emotional Blackmail Orientation of Salespeople. Procedia-Social and Behavioral Sciences, 5, 294-298. 
https://doi.org/10.1016/j.sbspro.2010.07.091

Christie, R., \& Geis, F. L. (1970). Studies in Machiavellianism. New York, NY: Academic Press.

Collins, N. L., \& Miller, L. C. (1994). Self-Disclosure and Liking: A Meta-Analytic Review. Psychological Bulletin, 116, 457-475. https://doi.org/10.1037/0033-2909.116.3.457

Colvin, C. R., \& Longueuil, D. (2001). Eliciting Self-Disclosure: The Personality and Behavioural Correlates of the Opener Scale. Journal of Research in Personality, 35, 238-246. https://doi.org/10.1006/jrpe.2000.2315

Cosby, P. C. (1973). Self-Disclosure: A Literature Review. Psychological Bulletin, 79, 73-91. https://doi.org/10.1037/h0033950

Curcuruto, M., Strauss, K., Axtell, C., \& Griffin, M. A. (2020). Voicing for Safety in the Workplace: A Proactive Goal-Regulation Perspective. Safety Science, 131, Article ID: 104901. https://doi.org/10.1016/j.ssci.2020.104902

Dahling, J. J., Whitaker, B. G., \& Levy, P. E. (2009). The Development and Validation of a New Machiavellianism Scale. Journal of Management, 35, 219-257.

https://doi.org/10.1177/0149206308318618

Deutsch, M. (1949). An Experimental Study of the Effects of Cooperation and Competition upon Group Process. Human Relations, 2, 199-231. https://doi.org/10.1177/001872674900200301

Deutsch, M. (1973). The Resolution of Conflict: Constructive and Destructive Processes. American Behavioral Scientist, 17, 248. https://doi.org/10.1177/000276427301700206

Dindia, K., \& Allen, M. (1992). Sex Differences in Self-Disclosure: Meta-Analysis. Psychological Bulletin, 112, 106-124. https://doi.org/10.1037/0033-2909.112.1.106

Erdley, C. A., \& Day, H. J. (2016). Friendship in Childhood and Adolescence. In M. Hojjat, \& A. Moyer (Eds.), The Psychology of Friendship (pp. 3-19). Oxford: Oxford University Press. https://doi.org/10.1093/acprof:oso/9780190222024.003.0001

Fehr, B., Samsom, E., \& Paulhus, D. L. (1992). The Construct of Machiavellianism: Twenty Years Later. In C. D. Spielberger, \& J. N. Butcher (Eds.), Advances in Personality Assessment (pp. 77-116). Hillsdale, NJ: Erlbaum.

Foster, G. (2005). Making Friends: A Nonexperimental Analysis of Social Pair Formation. Human Relations, 58, 1443-1465. https://doi.org/10.1177/0018726705061313

Fülöp, M. (2004). Competition as a Culturally Constructed Concept. In C. Baillie, E. Dunn, \& Y. Zheng (Eds.), Travelling Facts. The Social Construction, Distribution, and Accumulation of Knowledge (pp. 124-148). Frankfurt/New York: Campus Verlag.

Furnham, A., Richards, S. C., \& Paulhus, D. L. (2013). The Dark Triad of Personality: A 10 Year Review. Social and Personality Psychology Compass, 7, 199-216. https://doi.org/10.1111/spc3.12018

Harrell, W. A., \& Hartnagel, T. (1976). The Impact of Machiavellianism and the Trustfulness of the Victim on Laboratory Theft. Sociometry, 39, 157-165.

https://doi.org/10.2307/2786216

Hendrick, S. S., Hendrick, C., \& Adler, N. L. (1988). Romantic Relationships: Love, Satisfaction, and Staying Together. Journal of Personality and Social Psychology, 54, 980-988. https://doi.org/10.1037/0022-3514.54.6.980

Hodges, S. (2018). The Effect of Relationship Strength on Safety Voicing. Christchurch: University of Canterbury. http://hdl.handle.net/10092/15072

Holt-Lunstad, J. (2016). Friendship and Health. In M. Hojjat, \& A. Moyer (Eds.), The Psychology of Friendship (pp. 233-248). Oxford: Oxford University Press. 
Johnson, D. W., \& Johnson, R. T. (1989). Cooperation and Competition: Theory and Research. Edina, $\mathrm{MN}$ : International Book Co.

Jonason, P. K., \& Kavanagh, P. (2010). The Dark Side of Love: Love Styles and the Dark Triad. Personality and Individual Differences, 49, 606-610. https://doi.org/10.1016/j.paid.2010.05.030

Jonason, P. K., Li, N. P., Webster, G. D., \& Schmitt, D. P. (2009). The Dark Triad: Facilitating a Short-Term Mating Strategy in Men. European Journal of Psychology, 23, 5-18. https://doi.org/10.1002/per.698

Jones, D. N., \& Paulhus, D. L. (2009). Machiavellianism. In M. R. Leary, \& R. H. Hoyle (Eds.), Individual Differences in Social Behaviour (pp. 93-109). New York: Guilford.

Jones, D. N., Nickel, T. W., \& Schmidt, A. (1979). Machiavellianism and Self-Disclosure. Journal of Psychology, 102, 33-41. https://doi.org/10.1080/00223980.1979.9915092

Kessler, S. R., Bandelli, A. C. et al. (2010). Re-Examining Machiavelli: A Three-Dimensional Model of Machiavellianism in the Workplace. Journal of Applied Social Psychology, 40, 1868-1896. https://doi.org/10.1111/j.1559-1816.2010.00643.x

Kiazad, K., Restubog, S. L. D., Zagenczyk, T. J., Kiewitz, C., \& Tang, R. L. (2010). In Pursuit of Power: The Role of Authoritarian Leadership in the Relationship between Supervisors' Machiavellianism and Subordinates' Perceptions of Abusive Supervisory Behaviour. Journal of Research in Personality, 44, 512-519. https://doi.org/10.1016/j.jrp.2010.06.004

King, A. R., Russell, T., \& Veith, A. C. (2016). Friendship and Mental Health Functioning. In M. Hojjat, \& A. Moyer (Eds.), The Psychology of Friendship (pp. 249-266). Oxford: Oxford University Press. https://doi.org/10.1093/acprof:oso/9780190222024.003.0015

Kish-Gephart, J. J., Harrison, D. A., \& Trevino, L. K. (2010). Bad Apples, Bad Cases, and Bad Barrels: Meta-Analytic Evidence about Sources of Unethical Decisions at Work. Journal of Applied Psychology, 95, 1-31. https://doi.org/10.1037/a0017103

Lever, J. (1978). Sex Differences in the Complexity of Children's Play and Games. American Sociological Review, 43, 471-483. https://doi.org/10.2307/2094773

Lo, C. F., \& Ng, E. C. B. (2019). Machiavellianism and Intimacy Attitudes in the Interpersonal Relationships. Psychology, 10, 424-433.

https://doi.org/10.4236/psych.2019.104029

Lu, S. (2014). Safety Voicing: The Impact of Job Insecurity and the Differences in Severity of Safety Concerns. Masters Dissertation, Christchurch: University of Canterbury.

Lyons, M., \& Aiken, S. (2010). Machiavellian Friends? The Role of Machiavellianism in Friendship Formation and Maintenance. Journal of Social, Evolutionary and Cultural Psychology, 4, 194-202. https://doi.org/10.1037/h0099290

Martin, R. A., Lastuk, J. M., Jeffery, J., Vernon, P. A., \& Veselka, L. (2012). Relationships between Dark Triad and Humor Styles: A Replication and Extension. Personality and Individual Differences, 52, 178-182. https://doi.org/10.1016/j.paid.2011.10.010

McHoskey, J. W. (1995). Narcissism and Machiavellianism. Psychological Reports, 77, 753-759. https://doi.org/10.2466/pr0.1995.77.3.755

McHoskey, J. W. (1999). Machiavellianism, Intrinsic versus Extrinsic Goals, and Social Interest: A Self-Determination Theory Analysis. Motivation and Emotion, 23, 267-283. https://doi.org/10.1023/A:1021338809469

McHoskey, J. W. (2001). Machiavellianism and Sexuality: On the Moderating Role of Biological Sex. Personality and Individual Differences, 31, 779-789. 
https://doi.org/10.1016/S0191-8869(00)00180-X

McHoskey, J. W., Worzel, W., \& Szyarto, C. (1998). Machiavellianism and Psychopathy. Journal of Personality and Social Psychology, 74, 192-210. https://doi.org/10.1037/0022-3514.74.1.192

Miller, L. C., Berg, J. H., \& Archer, R. L. (1983). Openers: Individuals Who Elicit Intimate Self-Disclosure. Journal of Personality and Social Psychology, 44, 1234-1244. https://doi.org/10.1037/0022-3514.44.6.1234

Monsour, M. (1992). Meanings of Intimacy in Cross- and Same-Sex Friendships. Journal of Social and Personal Relationship, 9, 277-295. https://doi.org/10.1177/0265407592092007

Morrison, R. L., \& Cooper-Thomas, H. D. (2016). Friendship among Coworkers. In M. Hojjat, \& A. Moyer (Eds.), The Psychology of Friendship (pp. 123-140). Oxford: Oxford University Press. https://doi.org/10.1093/acprof:oso/9780190222024.003.0008

O’Boyle, E. H., Forsyth, D. R., Banks, G., \& McDaniel, M. A. (2012). A Meta-Analysis of the Dark Triad and Work Outcomes: A Social Exchange Perspective. Journal of Applied Psychology, 97, 557-579. https://doi.org/10.1037/a0025679

O’Connor, E. M., \& Simms, C. M. (1990). Self-Revelation as Manipulation: The Effects of Sex and Machiavellianism on Self-Disclosure. Social Behaviour and Personality, 18, 95-100. https://doi.org/10.2224/sbp.1990.18.1.95

Paulhus, D. L., \& Williams, K. M. (2002). The Dark Triad of Personality: Narcissism, Machiavellianism and Psychopathy. Journal of Research in Personality, 36, 556-563. https://doi.org/10.1016/S0092-6566(02)00505-6

Pegalis, L. J., Shaffer, D. R., Bazzini, D. G., \& Greenier, K. (1994). On the Ability to Elicit Self-Disclosure: Are There Gender-Based and Contextual Limitations on the Opener Effect? Personality and Social Psychology Bulletin, 20, 412-420. https://doi.org/10.1177/0146167294204008

Perlman, D. (2016). Friendship: An Echo, a Hurrah and Other Reflections. In M. Hojjat, \& A. Moyer (Eds.), The Psychology of Friendship (pp. 283-300). Oxford: Oxford University Press.

Ragsdale, J. D., \& Brandau-Brown, F. E. (2005). Individual Differences in the Use of Relational Maintenance Strategies in Marriage. The Journal of Family Communication, 5, 61-75. https://doi.org/10.1207/s15327698jfc0501_4

Rauthmann, J. F. (2012). Towards Multifaceted Machiavellianism: Content, Factorial, and Construct Validity of a German Machiavellianism Scale. Personality and Individual Differences, 52, 345-351. https://doi.org/10.1016/j.paid.2011.10.038

Rubin, L. B. (1985). Just Friends: The Role of Friendship in Our Lives (1st ed.). New York: Harper \& Low.

Sakalaki, M., Richardson, C., \& Thepaut, Y. (2007). Machiavellianism and Economic Opportunism. Journal of Applied Social Psychology, 37, 1181-1190. https://doi.org/10.1111/j.1559-1816.2007.00208.x

Sapadin, L. A. (1988). Friendship and Gender: Perspectives of Professional Men and Women. Journal of Social and Personal Relationships, 5, 387-403. https://doi.org/10.1177/0265407588054001

Shaffer, D. R., Ruammake, C., \& Pegalis, L. J. (1990). The “Opener”: Highly Skilled as Interviewer or Interviewee. Personality and Social Psychology Bulletin, 16, 511-520. https://doi.org/10.1177/0146167290163009

Sherry, S. B., Hewitt, P. L., Besser, A., Flett, G. L., \& Klein, C. (2006). Machiavellianism, Trait Perfectionism and Perfectionistic Self-Presentation. Personality and Individual 
Differences, 40, 829-839. https://doi.org/10.1016/j.paid.2005.09.010

Singleton, R. A., \& Vacca, J. (2007). Interpersonal Competition in Friendship. Sex Roles, 57, 617-627. https://doi.org/10.1007/s11199-007-9298-X

Spence, J. T., \& Helmreich, R. L. (1983). Achievement-Related Motives and Behaviors. In J. T. Spence (Ed.), Achievement and Achievement Motives: Psychological and Sociological Approaches (pp. 7-74). San Francisco, CA: W. H. Freeman.

Steinberg, S. (2007). An Introduction to Communication Studies. South Africa: Juta and Company, Ltd.

Sullivan, H. S. (1953). The Interpersonal Theory of Psychiatry. New York: Norton.

Tassi, F., \& Schneider, B. H. (1997). Task-Oriented versus Other-Referenced Competition: Differential Implications for Children's Peer Relations. Journal of Applied Social Psychology, 27, 1557-1580. https://doi.org/10.1111/j.1559-1816.1997.tb01613.x

Tesser, A., \& Moore, J. (1990). Independent Threats and Self-Evaluation Maintenance Processes. Journal of Social Psychology, 130, 677-689. https://doi.org/10.1080/00224545.1990.9922960

Van de Vliert, E. (1999). Cooperation and Competition as Partners. European Review of Social Psychology, 10, 231-257. https://doi.org/10.1080/14792779943000071

Vecchio, R. P., \& Sussman, M. (1991). Choice of Influence Tactics: Individual and Organizational Determinants. Journal of Organizational Behavior, 12, 73-80. https://doi.org/10.1002/job.4030120107

Vernon, P. A., Villani, V. C., Vickers, L. C., \& Harris, J. A. (2008). A Behavioural Genetic Investigation of the Dark Triad and the Big 5. Personality and Individual Differences, 44, 445-452. https://doi.org/10.1016/j.paid.2007.09.007

Veselka, L., Schermer, J. A., \& Vernon, P. A. (2012). The Dark Triad and an Expanded Framework of Personality. Personality and Individual Differences, 53, 417-423. https://doi.org/10.1016/j.paid.2012.01.002

Vogt, D. S., \& Colvin, C. (2003). Interpersonal Orientation and the Accuracy of Personality Judgments. Journal of Personality, 71, 267-295.

https://doi.org/10.1111/1467-6494.7102005

Wastell, C., \& Booth, A. (2003). Machiavellianism: An Alexithymic Perspective. Journal of Social and Clinical Psychology, 22, 730-744.

https://doi.org/10.1521/jscp.22.6.730.22931

Werking, K. (1997). We're Just Good Friends: Women and Men in Nonromantic Relationships. New York: Guildford.

Wheeless, L. R., \& Grotz, J. (1977). The Measurement of Trust and Its Relationship to Self-Disclosure. Human Communication Research, 3, 250-257.

https://doi.org/10.1111/j.1468-2958.1977.tb00523.x

Wicker, F. E., Thomas, R., \& McGrath, A. (2005). The Influence of Social-Disclosure in Committed Relationships. Journal of Human Relations, 32, 1005-1028.

Wilson, D. S., Near, D. C., \& Miller, R. R. (1996). Machiavellianism: A Synthesis of the Evolutionary and Psychological Literatures. Psychological Bulletin, 119, 285-299. https://doi.org/10.1037/0033-2909.119.2.285

Wilson, D. S., Near, D. C., \& Miller, R. R. (1998). Individual Differences in Machiavellianism as a Mix Cooperative and Exploitative Strategies. Evolution and Human Behavior, 19, 203-212. https://doi.org/10.1016/S1090-5138(98)00011-7 